\title{
Dynamics of telopodes (telocyte prolongations) in cell culture depends on extracellular matrix protein
}

\author{
Cristina Mariana Niculite - T. M. Regalia • \\ Mihaela Gherghiceanu • R. Huica • Mihaela Surcel • \\ C. Ursaciuc • M. Leabu • L. M. Popescu
}

Received: 1 July 2014/Accepted: 12 September 2014/Published online: 21 September 2014

(C) The Author(s) 2014. This article is published with open access at Springerlink.com

\begin{abstract}
Telocytes (TC) are cells with telopodes (Tp), very long prolongations (up to $100 \mu \mathrm{m}$ ) with an uneven caliber (www.telocytes.com). Factors determining the dynamics of cellular prolongations are still unknown, although previous studies showed telopode motility in TC cultures. We comparatively investigated, by time-lapse videomicroscopy, the dynamics of $\mathrm{Tp}$ of mouse heart TC seeded on collagen, fibronectin, and laminin. Under our experimental conditions, TC and fibroblasts (cell line L929) behaved differently in terms of adherence, spreading, and prolongation extension. Fibroblasts showed lower spreading on the matrix proteins used. The time needed for spreading was $2-4 \mathrm{~h}$ for TC, versus $8-10 \mathrm{~h}$ for fibroblasts. The values for final cell surface area after spreading were between 200 and $400 \mu \mathrm{m}^{2}$ for fibroblasts and $800-2,000 \mu \mathrm{m}^{2}$ for TC. TC
\end{abstract}

C. M. Niculite - T. M. Regalia - M. Leabu

Department of Cellular and Molecular Biology, "Victor Babeş"

National Institute of Pathology, Bucharest, Romania

C. M. Niculite - T. M. Regalia · R. Huica · M. Leabu ·

L. M. Popescu

Department of Cellular and Molecular Medicine, "Carol Davila"

University of Medicine and Pharmacy, Bucharest, Romania

M. Gherghiceanu

Laboratory of Electron Microscopy, "Victor Babeş" National

Institute of Pathology, Bucharest, Romania

R. Huica · M. Surcel · C. Ursaciuc

Department of Immunology, "Victor Babeş" National Institute

of Pathology, Bucharest, Romania

L. M. Popescu ( $₫)$

Division of Advanced Studies, "Victor Babeş" National Institute

of Pathology, 99-101 Splaiul Independentei, Sector 5,

050096 Bucharest, Romania

e-mail: 1popescu@jcmm.org showed a more than three times higher ability to spread on the tested matrix proteins. An extremely low capacity to extend prolongations with lengths shorter than cell bodies was noted for fibroblasts, while TC extended prolongations longer than the cell body length, with a moniliform appearance. The stronger adherence and spreading were noted for TC seeded on fibronectin, while the lowest were on laminin. Collagen determined an intermediate adherence and spreading for TC, but the highest dynamics in Tp extensions. In conclusion, TC behave differently than fibroblasts in terms of adherence, spreading, and cell prolongation extension when seeded on various matrix proteins in cell culture.

Keywords Telocyte - Telopodes $\cdot$ Collagen ·

Fibronectin - Laminin - Time-lapse videomicroscopy ·

Cell layer impedance

\section{Introduction}

Telocytes (TC) are interstitial cells extending very long cytoplasmic processes named telopodes (Tp) [1], exhibiting moniliform appearance, due to podomers and podoms [2]. TC are considered cells which integrate tissue components for a coherent function by intercellular signaling following different mechanisms [3], by stromal synapses [3, 4], and by ectosomes [5]. There are several reports suggesting these cells' commitment in tissue regeneration [6-12]. Therefore, the telocytes' ability to extend Tp and the dynamics of these prolongations seem to be important for the cell function, including their activity in regenerative events. Dynamics of telocytes' $\mathrm{Tp}$ is a challenging topic due to their ability to facilitate homo- and hetero-cellular contacts, which modulate the functions of other cells (e.g., myocytes, immune cells, stem cells, epithelial and nerve 
cells) in various organs [4, 13-15]. Furthermore, TC are proven to be different from fibroblasts and mesenchymal stem cells in terms of gene profile and proteomics [16-18], and even in microRNA expression [19]. Moreover, the interest for modulating the dynamics of telocytes' $\mathrm{Tp}$ increases continuously due to the possibility to use cell behavior as a target in tissue regeneration [20]. Dynamics of Tp could follow mechanisms similar to those acting in cell motility, but no reported results exist so far for TC.

Cell motility is a highly dynamic event, subtly tuned, carefully regulated, accompanied by cell shape changes, and cytoskeleton reorganization, under a rigorous control and modulation by complex mechanisms involving cell adherence, spreading, and reversibility of integrins to matrix proteins interactions controlled by integrin cytoplasmic tail interactions with various interactors [21-23]. Cell motility, in terms of spreading only, or even cell movement needs cross talk of various signaling events triggered by both cyto-, chemo- or hapto-taxis factors [24, 25], and other transmembrane (glyco)proteins (integrins and/or proteoglycans) [22, 24-26]. Moreover, cell motility, including cell prolongation extension (acting in cell spreading and locomotion), requires a high coordination of several events such as successive adhesions and detachments of the cells, by interacting with the extracellular matrix, and accompanied by changes in the cell shape eliciting cytoskeleton rearrangement [22, 27-30]. These events, that are highly controlled and modulated by the cell, result in an adequate mechanical behavior. All of the above mentioned events occur while the cells are involved in chemotaxis or haptotaxis. Cell motility was proven to depend on the strength of interactions between integrins and matrix proteins [28]. Both low adhesiveness and strong attachment to the matrix proteins impede the cell dynamics.

We report here results on the dynamics of $\mathrm{TC}$ versus fibroblasts on different matrix proteins, showing differences between the two types of cells in their ability to extend prolongations that depends on matrix proteins used to cover the culture surface.

\section{Materials and methods}

\section{Cell culture}

TC were investigated in a highly enriched culture of interstitial cells from mouse hearts. The hearts were dissected under a stereomicroscope, minced into millimetric pieces and dissociated by enzymatic digestion as described elsewhere [2]. Cultured TC in mouse heart were harvested using trypsin-EDTA in PBS and prepared for time-lapse videomicroscopy by suspending them at a density of
$5 \times 10^{3}$ cells $/ \mathrm{ml}$ in DMEM/F12 culture medium, supplemented with $10 \%$ fetal calf serum and $100 \mathrm{U} / \mathrm{ml}$ penicillin $-100 \mu \mathrm{g} / \mathrm{ml}$ streptomycin (all reagents from SigmaAldrich).

L929 mouse fibroblasts were grown in the same culture medium, but were harvested using PBS-EDTA and suspended for experiments at the same concentration, $5 \times 10^{3} \mathrm{cells} / \mathrm{ml}$.

\section{Flow cytometry}

TC content in our enriched culture was assessed by doublelabeling with Alexa Fluor 637-conjugated anti-vimentin monoclonal antibodies and PerCP-labeled anti-CD34 monoclonal antibodies (Santa Cruz Biotechnology Inc. Heidelberg, Germany) and analyzed in a BD FACSCanto II cytometer. Unlabeled cells were used as a control (Fig. 1) in order to avoid counting of false positive cells. Nonspecific fluorescence signals due to spectral overlapping were automatically compensated for, using BD CompBeads particles. Data acquisition and analysis were performed with BD FACSDiva 6.1 software.

Experiments for cell adherence and spreading by impedance measurements

Sixteen-well E-plates designed for the xCELLigence system (Roche Diagnostics, Mannheim, Germany) were prepared for adherence and spreading of cells in enriched interstitial cell samples and of fibroblasts as follows: four wells without any matrix protein (for control), four wells for collagen I (Coll), four wells for fibronectin (Fn), and four wells for laminin (Lam). Matrix proteins used for coating were solubilized in $0.1 \mathrm{M} \mathrm{NaHCO}_{3}$, at $5 \mu \mathrm{g} / \mathrm{ml}$. Coating was done overnight, at $4{ }^{\circ} \mathrm{C}$ [31], by using $50 \mu \mathrm{l}$ of matrix protein solution for each well. The wells were washed twice with plain medium, and background values of impedance were measured in serum-free medium, supplemented with $5 \%$ bovine serum albumin (BSA-medium). Following this step, $2 \times 10^{3}$ cells were added to each well, and the cell layer impedance was recorded for $18 \mathrm{~h}$.

Preparation of culture dishes

Culture dishes with four chambers $\left(\mathrm{Hi}-\mathrm{Q}^{4} 35 \mathrm{~mm}\right.$ Dishes, Ibidi GmbH, Martinsried, Germany) were used to simultaneously monitor the cell behavior in four different experimental conditions. These dishes were specially designed for BioStation IM (Nikon Corp. Kawasaki, Japan), equipment for time-lapse videomicroscopy experiments. The dishes were prepared as follows: (i) one chamber for control, without any matrix protein; (ii) the other three chambers were coated with Coll, Fn, and Lam, 
Fig. 1 Representative results of flow cytometry assay by BD FACSCanto II cytometer for cultured interstitial cells obtained from rat heart. Control unlabeled cells. Sample cells labeled for rat vimentin and rat $\mathrm{CD} 34$

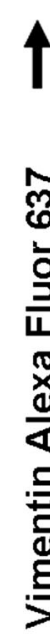

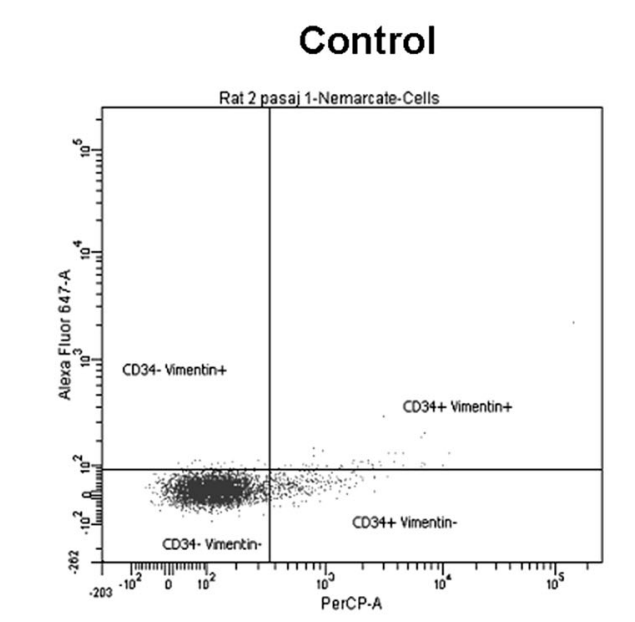

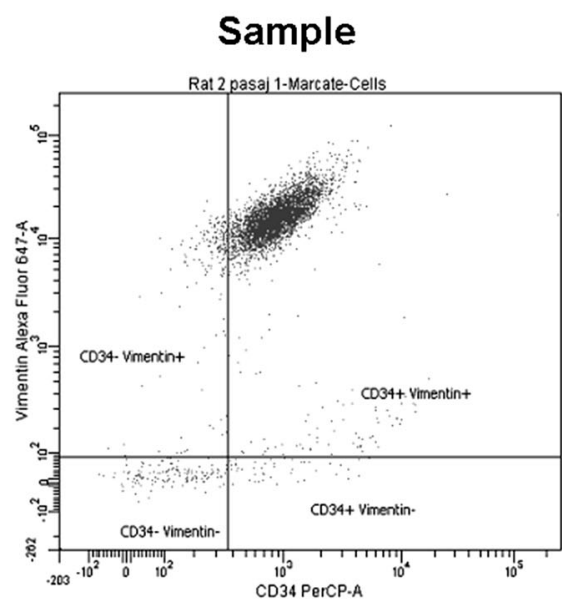

\section{CD34 PerCP}

respectively. For coating, $300 \mu \mathrm{l}$ of matrix protein solution at $5 \mu \mathrm{g} / \mathrm{ml}$, in $0.1 \mathrm{M} \mathrm{NaHCO}_{3}$ were used overnight, at $4{ }^{\circ} \mathrm{C}$. After washing with PBS, the dishes were ready for cell seeding in BSA-medium.

Time-lapse videomicroscopy

Cells were seeded on the dish $(300 \mu \mathrm{l}$ cell suspension/ chamber) and, after a $10 \mathrm{~min}$ incubation period at $37^{\circ} \mathrm{C}$ and $5 \% \mathrm{CO}_{2}$, to promote cell adhesion, the dish was placed in BioStation IM to monitor adherence, spreading, and morphology dynamics of cells. Images were collected for $24 \mathrm{~h}$ every $5 \mathrm{~min}$, in five different microscopic fields from each chamber. Data were collected from images by counting the number of moniliform prolongations, longer than the cell length, for cells present in the selected fields. To assess cell spreading the contours of cells were traced using the NIS Element BR software, which allows the user to determine the cell surface. Average values \pm standard errors of media were plotted as a function of experimental time.

\section{Electron microscopy}

Transmission electron microscopy (TEM) was performed on cultured cells (TC or fibroblasts) fixed with $2.5 \%$ glutaraldehyde in $0.1 \mathrm{M}$ cacodylate buffer, directly in the culture dish. The samples were post-fixed in $1 \% \mathrm{OsO}_{4}$ with $1.5 \% \mathrm{~K}_{4} \mathrm{Fe}(\mathrm{CN})_{6}$ (potassium ferrocyanide-reduced osmium). Subsequently, cells were embedded in $1 \%$ agar, dehydrated in graded ethanol series, and embedded in epoxy resin (Agar 100) [32]. The ultra-thin sections were cut with a diamond knife at a $60 \mathrm{~nm}$ thickness using an
RMC ultramicrotome (Boeckeler Instruments Inc., Tucson, AZ, USA) and were double stained with uranyl acetate and lead citrate. Ultrastructural examination was performed with a Morgagni 286 transmission electron microscope (FEI Company, Eindhoven, The Netherlands) at $80 \mathrm{kV}$. Digital electron micrographs were recorded with a MegaView III CCD and iTEM-SIS software (Olympus, Soft Imaging System GmbH, Münster, Germany).

\section{Statistical analysis}

Morphological data are presented as average values \pm standard errors of media. Statistical significance was assessed by Student's t test.

\section{Results and discussion}

Characterization of interstitial cells in mouse heart samples enriched in TC

Cells obtained from mouse hearts were tested by flow cytometry with double-labeling for vimentin and CD34 (Fig. 1), the markers proven to constantly characterize TC in many tissues $[3,15,33]$. We used flow cytometry for checking both homogeneity and phenotype of our isolated and cultured cells along the passages needed to our experiments to be done. Results showed that the cells are quite homogeneous in terms of morphological features (size and granularity), but by double-labeling for vimentin and CD34 the primary and cultured cell populations showed to be also highly homogeneous with only few percentages carrying a putative different phenotype. The 
Fig. 2 Results for flow cytometry analysis of rat heart interstitial cells; primary versus three successive passages in culture. A Average values as percent of cells labeled for CD34 and vimentin for four experiments at all passages. B Variation of percent of double-positive cells $(\mathrm{CD} 34+$ vimentin+) along the four passages
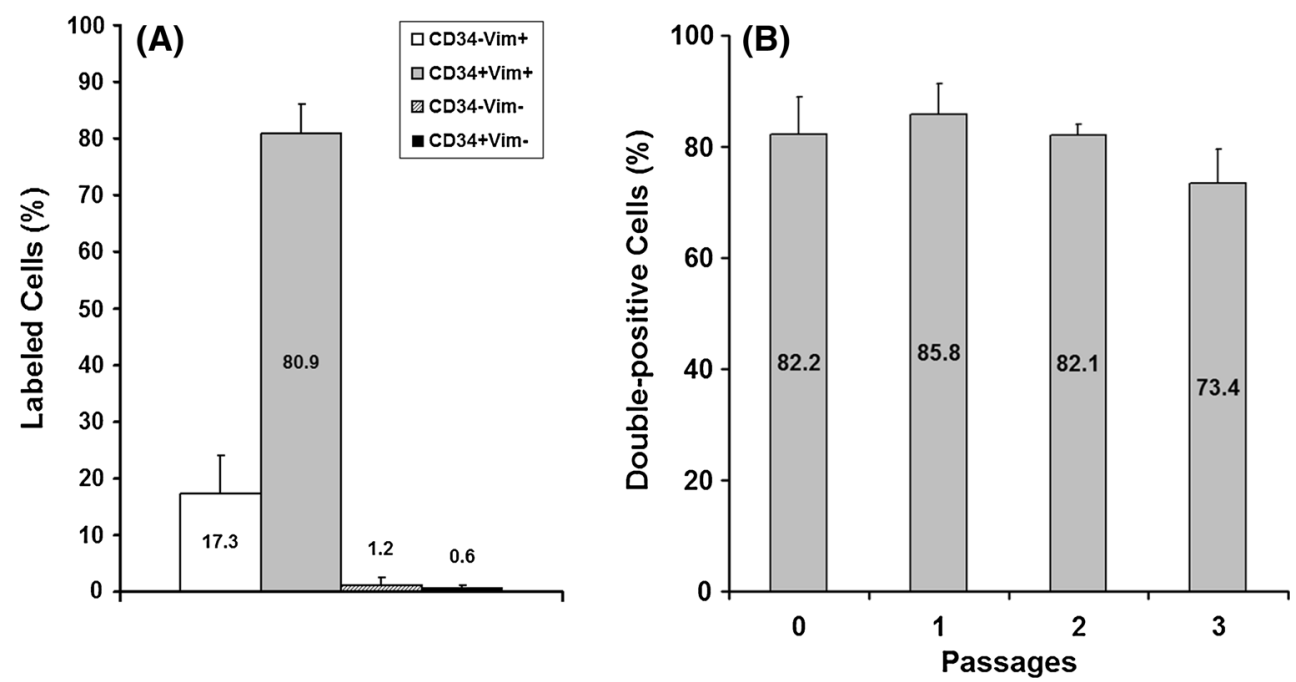

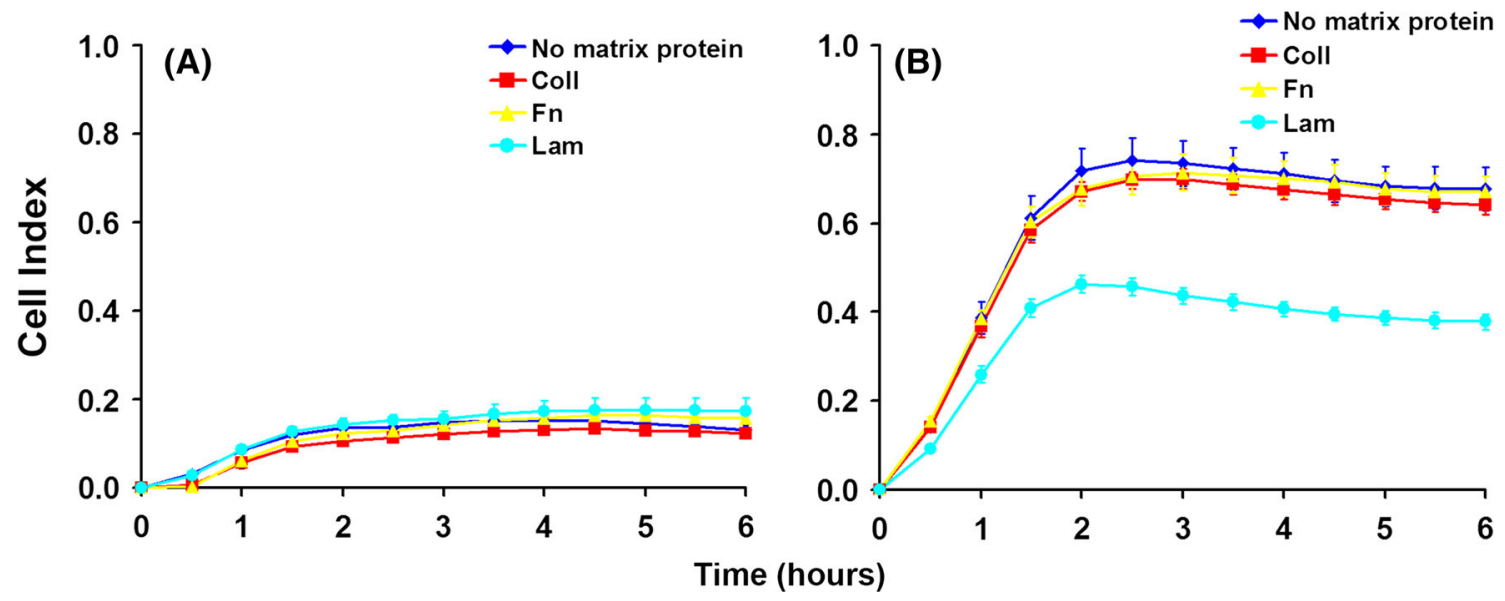

Fig. 3 Dynamics of cell spreading on different matrix proteins, monitored by measurement of the cell layer impedance. A Spreading of L929 fibroblasts. B Spreading of telocytes

results of four determinations during four cell passages revealed the presence in culture of double-positive cells (vimentin+CD34+) in an average proportion of $80.9 \pm 5.3 \%$ (Fig. 2A). Other cell types found in our samples were not double positive: CD34-vimentin+ $(17.3 \%), \quad$ CD34-Vimentin- (1.2\%), and CD34+ Vimentin- $(0.6 \%)$. The percent of double-positive cells slightly increased after the first passage in comparison with samples of primary cells, but the following three passages showed a slight downward trend: 82.2, 85.8, 82.1, $73.4 \%$ (Fig. 2B). This decreasing trend for double-positive cells in culture along passages could be due to a putative low proliferation rate for TC. We did not chase the other cell types, such as CD34-vimentin+ (representing less than one out of five cells) in our time-lapse videomicroscopy experiments, to appreciate if they could be identified as different cells by morphological features. Moreover, nothing drew our attention in terms of different morphology of cells monitored in the experimental fields. This fact confirmed what flow cytometry showed regarding the homogeneity of major double-positive cell population (granularity and size).

In conclusion, according to our flow cytometry results, in the experiments reported in this paper TC were the main type of cells in culture.

\section{Dynamics of cell spreading}

For a cell to extend prolongations it needs to adhere and spread first. Cell adherence and spreading were monitored by measuring the impedance of the cell layer using the xCELLigence system. L929 fibroblasts showed a similar low spreading on every matrix protein and on the uncoated control surface (Fig. 3A). This fact suggests a rather nonspecific adherence and spreading perhaps as a result of the production and secretion of the cells' own matrix proteins, 


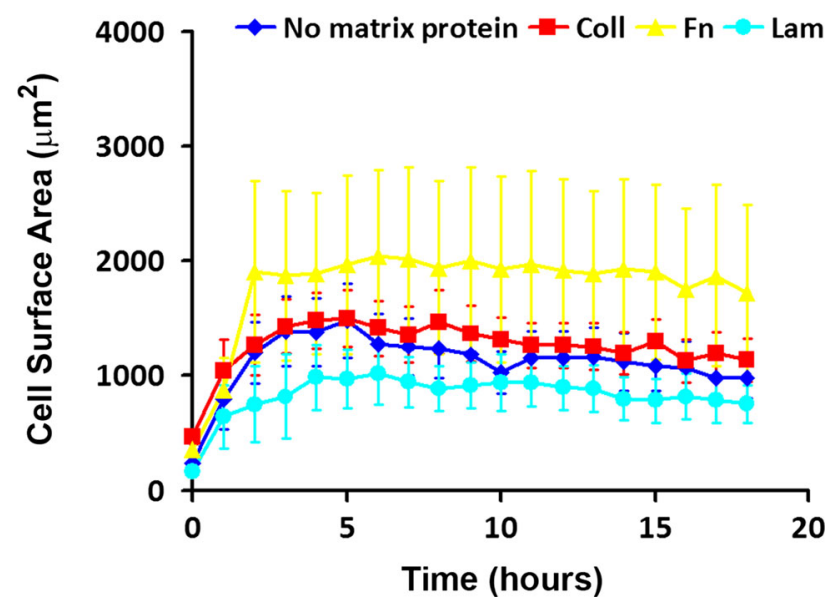

Fig. 4 Dynamics of telocyte spreading on different matrix proteins evidenced by the measurement of the cell surface area in time-lapse videomicroscopy experiments. The variability of surface area for the same cell at different experimental time points explains the high error bars on the plots expressing the huge dynamics in cell morphology

during the experiments. Cells in TC enriched samples proved a significantly lower adherence and spreading on laminin, while for control (no matrix), Coll, and Fn experiments, the adherence and spreading did not show differences (Fig. 3B). We reason that the observed differences could be explained as an effect of the diversity of cells in the samples. The global similar value of the impedance recorded when the cells were seeded on different matrix proteins could be due to the fact that the variations in the individual cell morphology dynamics are hidden by canceling each other. Therefore, we investigated the adherence and spreading of TC in time-lapse videomicroscopy experiments. The surface area of any identified TC was measured by tracing the contour of the cell shape, which resulted in a digital measurement done by the software application. According to this assessment, the results showed that TC have different spreading dynamics (Fig. 4).

TC spread in $2-4 \mathrm{~h}$ on every matrix protein with no significant difference in terms of spreading time. However, the spreading ability is different, depending on the matrix protein used for surface coating, by reaching different average spreading areas. The largest areas were obtained by spreading on Fn, while the smallest were noted on Lam. Spreading on Coll and in control experiments (no matrix protein on the culture surface) was quite similar. Fibroblasts showed a lower spreading dynamics needing $8-10 \mathrm{~h}$ in both control experiments, and on Coll, Fn, or Lam (not shown). Surprisingly, in our experimental conditions the spreading surface of the fibroblasts is growing continuously even at $18 \mathrm{~h}$. Moreover, the fibroblasts seeded on a surface with no matrix and on Lam proved a lower ability to spread in terms of cell surface area, while the spreading on Coll and Fn seems to be faster and larger.

The ability of TC to spread in any experimental conditions used was obviously higher (between $\sim 800$ and
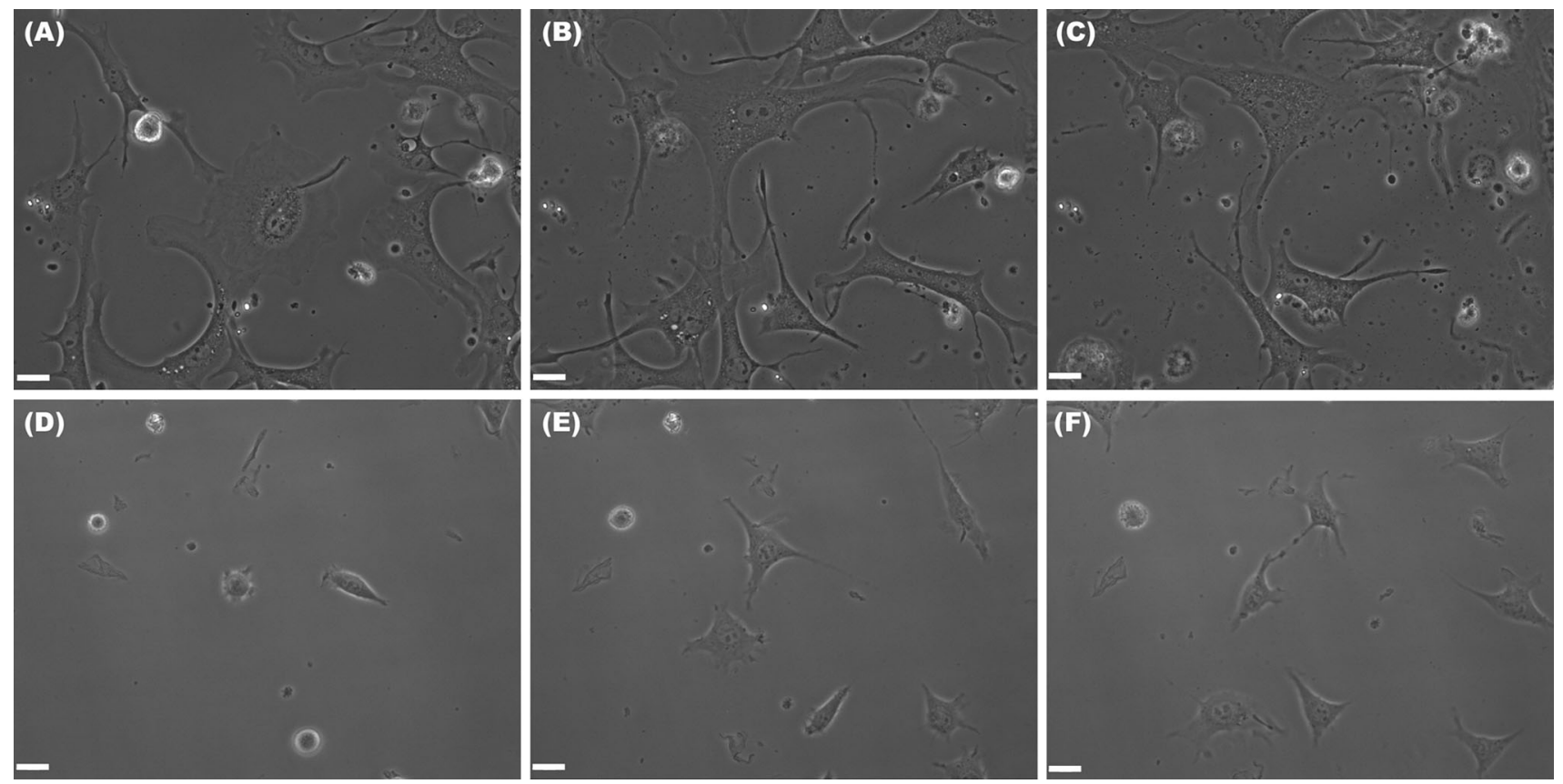

Fig. 5 Spreading of telocytes $(\mathbf{A}, \mathbf{B}, \mathbf{C})$ and fibroblasts $(\mathbf{D}, \mathbf{E}, \mathbf{F})$ on collagen I. The size of telocytes is higher in comparison with that of fibroblasts at any experimental time point. $\mathbf{A}$ and $\mathbf{D}$ cell spreading at
$4 \mathrm{~h}$ after seeding; $\mathbf{B}$ and $\mathbf{E}$ spreading at $12 \mathrm{~h} ; \mathbf{C}$ and $\mathbf{F}$ spreading at 18 h. Bar $20 \mu \mathrm{m}$ 
Fig. 6 Electron micrographs comparing the morphological and ultrastructural features of telocytes and fibroblasts. The main image: a telocyte extending a convoluted telopode about $120 \mu \mathrm{m}$ long, with podomers and podoms. Inset a fibroblast shown at the same magnification as the telocyte

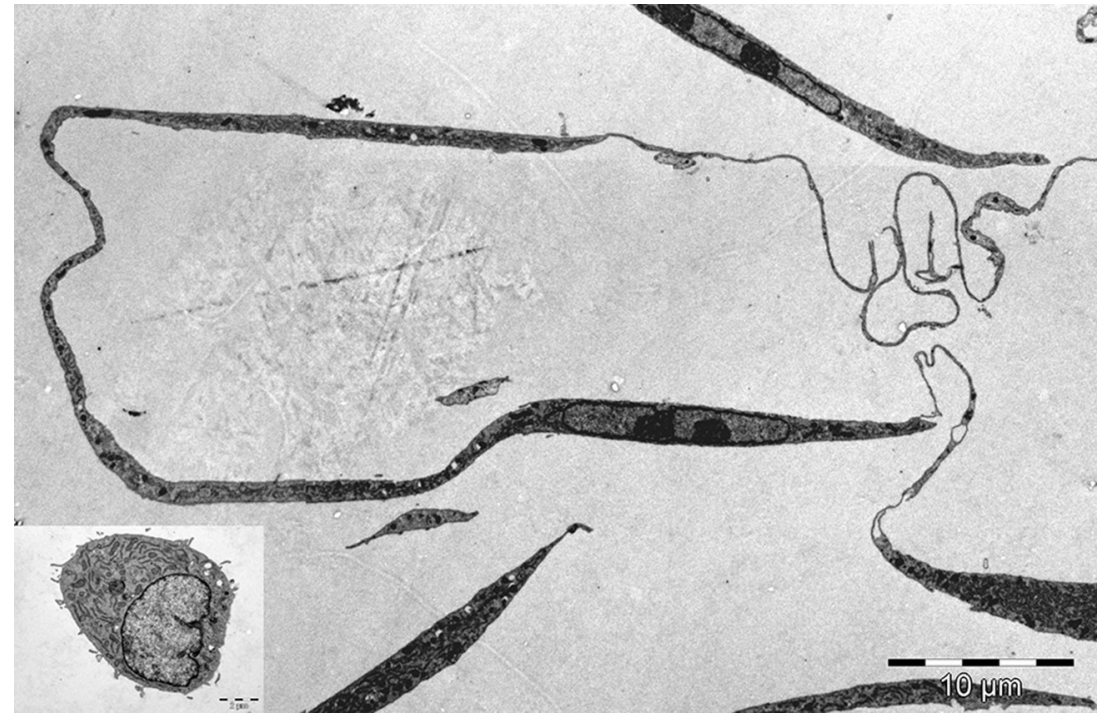

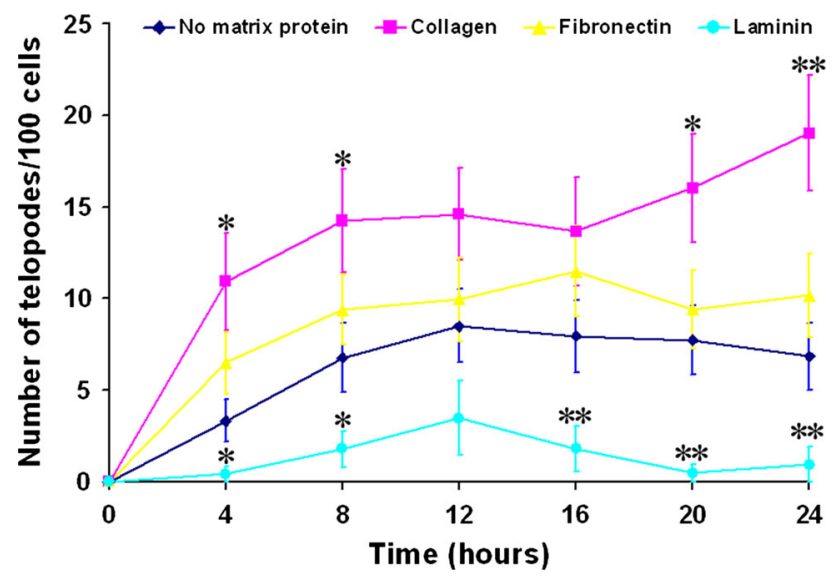

Fig. 7 Dynamics of telocytes' $\mathrm{Tp}$ extension on different matrix proteins used to prepare the surface culture compared to the standard culture surface (no matrix protein) as control. Symbols $*(p<0.05)$ and $* *(p<0.01)$ point out the statistical significance of the data at different experimental point times, in comparison with control values (no extracellular matrix protein covering the culture surface)

$\sim 2,000 \mu \mathrm{m}^{2}$ ), while fibroblasts spread on lower areas $\left(200-400 \mu \mathrm{m}^{2}\right)$. The results are in accordance with the spreading ability registered in experiments monitoring the cell layer impedance. The dimensional differences between TC and fibroblasts are suggestively noted in phase microscopy images captured in BioStation IM (Fig. 5). The morphological differences observed for cells used in timelapse videomicroscopy experiments have been also noted on cells prepared for TEM (Fig. 6). Moreover, electron micrographs' analysis proved the utility of "platinum standard" [34] to differentiate between TC and fibroblasts, while the recent investigations reported differences for both gene profile and proteomics between cells in our culture, highly enriched interstitial cells from mouse heart and fibroblasts or other interstitial cells [16-18]. An up-todate review is available [35].

Dynamics of prolongations' extension

The highest ability of $\mathrm{TC}$ to extend $\mathrm{Tp}$ is proven when seeded on Coll, while the fewest number of prolongations appeared for cells on Lam (Fig. 7). That makes sense, because TC were never observed interacting with basal laminae, in any of the tissues investigated. The highest dynamics of telocytes' $\mathrm{Tp}$, on surfaces coated with collagen $\mathrm{I}$, is supported by the lower adherence and spreading on this matrix protein, while the higher adherence and spreading on fibronectin impede TC to easily extend Tp. Therefore, the balance in the strength of forces developed by TC for adherence and spreading on collagen I allows the cells to extend $\mathrm{Tp}$ with a higher dynamics. We may hypothesize that collagen I, the most abundant matrix protein, present in most connective tissues and almost in all organs, could represent the best track for TC to direct the extending $\mathrm{Tp}$ toward the interaction partners, other cells in tissues, to organize, reorganize, or regenerate biological structures. Moreover, considering the observation in our experiments, cells do not usually extend simultaneously more than one $\mathrm{Tp}$, we may affirm that the values in Fig. 7 represent percents of cells simultaneously extending $\mathrm{Tp}$. Despite the fact that our samples are highly enriched in TC (around $80 \%$ as proven by flow cytometry results, using double-labeling), only a fraction extends $\mathrm{Tp}$ at the same time, with the highest stimulation on collagen.

The mouse fibroblasts tested in our experiments showed a totally different morphology dynamics, in terms of extending cell processes. It is noteworthy, L929 fibroblasts showed a very low ability to extend even short and non- 
moniliform prolongations, on all tested matrix proteins. There was no prolongation longer then cell body noted. These results proved that TC in our samples of enriched interstitial cells from mouse heart and cultured fibroblasts behave differently.

\section{Conclusions}

Our results showed TC seeded on various matrix proteins behave differently in terms of adherence, spreading, and dynamics of Tp extension. The highest telocyte adherence and spreading occurred on fibronectin, but the highest dynamics of Tp extension was noted for the cells seeded on collagen I. Comparatively, time-lapse investigation of TC and fibroblast behavior showed significant differences in terms of adherence, spreading, and ability to extend prolongations. This is the first comparative study about the dynamics of TC versus fibroblast morphology, confirming that our cultured cells obtained from mouse heart, as samples enriched in interstitial cells, contain cells that behave differently as compared with the mouse fibroblast cell line L929.

Acknowledgments This paper is partly supported by the Sectorial Operational Programme Human Resources Development (SOPHRD), financed by the European Social Fund and the Romanian Government under the contract number POSDRU 141531 (a fellowship awarded to Dr. Radu Huica). This article is also supported by the Romanian Ministry of Education, grant PN09 330205.

Open Access This article is distributed under the terms of the Creative Commons Attribution License which permits any use, distribution, and reproduction in any medium, provided the original author(s) and the source are credited.

\section{References}

1. Popescu LM, Faussone-Pellegrini MS (2010) Telocytes-a case of serendipity: the winding way from interstitial cells of cajal (ICC), via interstitial cajal-like cells (ICLC) to telocytes. J Cell Mol Med 14:729-740

2. Suciu L, Nicolescu MI, Popescu LM (2010) Cardiac telocytes: serial dynamic images in cell culture. J Cell Mol Med 14:2687-2692

3. Gherghiceanu M, Popescu LM (2012) Cardiac telocytes-their junctions and functional implications. Cell Tissue Res 348(2):265-279. doi:10.1007/s00441-012-1333-8

4. Popescu LM, Gherghiceanu M, Cretoiu D, Radu E (2005) The connective connection: interstitial cells of Cajal (ICC) and ICClike cells establish synapses with immunoreactive cells. Electron microscope study in situ. J Cell Mol Med 9:714-730

5. Nicolescu MI, Popescu LM (2012) Telocytes in the interstitium of human exocrine pancreas: ultrastructural evidence. Pancreas 41(6):949-956. doi:10.1097/MPA.0b013e31823fbded

6. Li L, Lin M, Li L, Wang R, Zhang C, Qi G, Xu M, Rong R, Zhu $\mathrm{T}$ (2014) Renal telocytes contribute to the repair of ischemically injured renal tubules. J Cell Mol Med. doi:10.1111/jcmm.12274
7. Galiger C, Kostin S, Golec A, Ahlbrecht K, Becker S, Gherghiceanu M, Popescu LM, Morty RE, Seeger W, Voswinckel R (2014) Phenotypical and ultrastructural features of Oct4-positive cells in the adult mouse lung. J Cell Mol Med. doi:10.1111/jcmm. 12295

8. Bani D, Nistri S (2014) New insights into the morphogenic role of stromal cells and their relevance for regenerative medicine. Lessons from the heart. J Cell Mol Med 18(3):363-370. doi:10. $1111 / \mathrm{jcmm} .12247$

9. Luesma MJ, Gherghiceanu M, Popescu LM (2013) Telocytes and stem cells in limbus and uvea of mouse eye. J Cell Mol Med 17(8):1016-1024. doi:10.1111/jcmm.12111

10. Ceafalan L, Gherghiceanu M, Popescu LM, Simionescu O (2012) Telocytes in human skin-are they involved in skin regeneration? J Cell Mol Med 16(7):1405-1420. doi:10.1111/j.1582-4934.2012. 01580.x

11. Manole CG, Cismaşiu V, Gherghiceanu M, Popescu LM (2011) Experimental acute myocardial infarction: telocytes involvement in neo-angiogenesis. J Cell Mol Med 15(11):2284-2296. doi:10. 1111/j.1582-4934.2011.01449.x

12. Popescu LM, Manole E, Serboiu CS, Manole CG, Suciu LC, Gherghiceanu M, Popescu BO (2011) Identification of telocytes in skeletal muscle interstitium: implication for muscle regeneration. J Cell Mol Med 15(6):1379-1392. doi:10.1111/j.1582-4934. 2011.01330.x

13. Cretoiu D, Cretoiu SM, Simionescu AA, Popescu LM (2012) Telocytes, a distinct type of cell among the stromal cells present in the lamina propria of jejunum. Histol Histopathol 27:1067-1078

14. Popescu LM, Nicolescu MI (2013) Telocytes and stem cells. In: dos Santos Goldenberg RC, de Campos Carvalh AC (eds) Resident stem cells and regenerative therapy. Academic Press, Oxford, pp 205-231

15. Cretoiu SM, Cretoiu D, Marin A, Radu BM, Popescu LM (2013) Telocytes: ultrastructural, immunohistochemical and electrophysiological characteristics in human myometrium. Reproduction 145(4):357-370. doi:10.1530/REP-12-0369

16. Sun X, Zheng M, Zhang M, Qian M, Zheng Y, Li M, Cretoiu D, Chen C, Chen L, Popescu LM, Wang X (2014) Differences in the expression of chromosome 1 genes between lung telocytes and other cells: mesenchymal stem cells, fibroblasts, alveolar type II cells, airway epithelial cells and lymphocytes. J Cell Mol Med 18(5):801-810. doi:10.1111/jcmm.12302

17. Zheng Y, Zhang M, Qian M, Wang L, Cismasiu VB, Bai C, Popescu LM, Wang X (2013) Genetic comparison of mouse lung telocytes with mesenchymal stem cells and fibroblasts. J Cell Mol Med 17(4):567-577. doi:10.1111/jcmm.12052

18. Zheng Y, Cretoiu D, Yan G, Cretoiu SM, Popescu LM, Wang X (2014) Comparative proteomic analysis of human lung telocytes with fibroblasts. J Cell Mol Med 18(4):568-589. doi:10.1111/ jcmm. 12290

19. Cismasiu VB, Radu E, Popescu LM (2011) miR-193 expression differentiates telocytes from other stromal cells. J Cell Mol Med 15(5):1071-1074. doi:10.1111/j.1582-4934.2011.01325.x

20. Campeanu RA, Radu BM, Cretoiu SM, Banciu DD, Banciu A, Cretoiu D, Popescu LM (2014) Near infrared low-level laser stimulation of telocytes from human myometrium. Lasers Med Sci. doi:10.1007/s10103-014-1589-1

21. Fogh BS, Multhaupt HA, Couchman JR (2014) Protein kinase $\mathrm{C}$, focal adhesions and the regulation of cell migration. J Histochem Cytochem 62(3):172-184. doi:10.1369/0022155413517 701

22. Morse EM, Brahme NN, Calderwood DA (2014) Integrin cytoplasmic tail interactions. Biochemistry 53(5):810-820. doi:10. 1021/bi401596q 
23. Kim C, Ye F, Hu X, Ginsberg MH (2012) Talin activates integrins by altering the topology of the $\beta$ transmembrane domain. J Cell Biol 197(5):605-611. doi:10.1083/jcb.201112141

24. Matsuo I, Kimura-Yoshida C (2013) Extracellular modulation of fibroblast growth factor signaling through heparan sulfate proteoglycans in mammalian development. Curr Opin Genet Dev 23(4):399-407. doi:10.1016/j.gde.2013.02.004

25. Jacquemet G, Humphries MJ, Caswell PT (2013) Role of adhesion receptor trafficking in 3D cell migration. Curr Opin Cell Biol 25(5):627-632. doi:10.1016/j.ceb.2013.05.008

26. Elfenbein A, Simons M (2013) Syndecan-4 signaling at a glance. J Cell Sci 126(Pt 17):3799-3804. doi:10.1242/jcs.124636

27. Ridley AJ, Schwartz MA, Burridge K, Firtel RA, Ginsberg MH, Borisy G, Parsons JT, Horwitz AR (2003) Cell migration: integrating signals from front to back. Science 302:1704-1709

28. Palecek SP, Huttenlocher A, Horwitz AF, Lauffenburger DA (1998) Physical and biochemical regulation of integrin release during rear detachment of migrating cells. J Cell Sci 111:929-940

29. Palecek SP, Schmidt CE, Lauffenburger DA, Horwitz AF (1996) Integrin dynamics on the tail region of migrating fibroblasts. J Cell Sci 109:941-952
30. Lauffenburger DA, Horwitz AF (1996) Cell migration: a physically integrated molecular process. Cell 84:359-369

31. Leabu M, Uniyal S, Xie J, Xu YQ, Vladau C, Morris VL, Chan BM (2005) Integrin $\alpha 2 \beta 1$ modulates EGF stimulation of Rho GTPase-dependent morphological changes in adherent human rhabdomyosarcoma RD cells. J Cell Physiol 202:754-766

32. Gherghiceanu M, Barad L, Novak A, Reiter I, Itskovitz-Eldor J, Binah O, Popescu LM (2011) Cardiomyocytes derived from human embryonic and induced pluripotent stem cells: comparative ultrastructure. J Cell Mol Med 15:2539-2551

33. Gevaert T, De Vos R, Van Der Aa F, Joniau S, van den Oord J, Roskams T, De Ridder D (2012) Identification of telocytes in the upper lamina propria of the human urinary tract. J Cell Mol Med 16(9):2085-2093

34. Popescu LM, Ciontea SM, Cretoiu D (2007) Interstitial Cajal-like cells in human uterus and fallopian tube. Ann N Y Acad Sci 1101:139-165

35. Cretoiu SM, Popescu LM (2014) Telocytes revisited. Biomol Concepts. doi:10.1515/bmc-2014-0029 